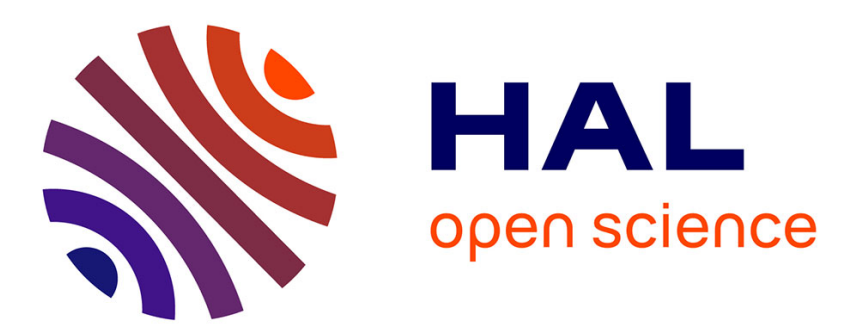

\title{
Dispositional Mindfulness Profiles and Cannabis Use in Young Adults
}

\author{
Jonathan Bronchain, Patrick Raynal, Henri Chabrol
}

\section{To cite this version:}

Jonathan Bronchain, Patrick Raynal, Henri Chabrol. Dispositional Mindfulness Profiles and Cannabis Use in Young Adults. Journal of Rational-Emotive and Cognitive-Behavior Therapy, 2020, 39, pp.509521. 10.1007/s10942-020-00382-z . hal-03197021

\section{HAL Id: hal-03197021 \\ https://hal.science/hal-03197021}

Submitted on 13 Apr 2021

HAL is a multi-disciplinary open access archive for the deposit and dissemination of scientific research documents, whether they are published or not. The documents may come from teaching and research institutions in France or abroad, or from public or private research centers.
L'archive ouverte pluridisciplinaire HAL, est destinée au dépôt et à la diffusion de documents scientifiques de niveau recherche, publiés ou non, émanant des établissements d'enseignement et de recherche français ou étrangers, des laboratoires publics ou privés. 
Dispositional Mindfulness Profiles and Cannabis Use in Young Adults

Jonathan Bronchain, Patrick Raynal and Henri Chabrol

Centre d'Etudes et de Recherches en Psychopathologie et Psychologie de la Santé, Université de Toulouse, UT2J, France

Corresponding author:

J. Bronchain, UFR de Psychologie, Université de Toulouse-Jean Jaurès, 5 allées Antonio Machado, 31058 Toulouse cedex 9

phone number: 33781533109

fax number: 33561257093

e-mail address: jonathan.bronchain@etu.univ-tlse2.fr 


\begin{abstract}
The relationships between dispositional mindfulness and cannabis use remain understudied. The aim of the present study was to link cannabis use and problematic use with different profiles based on dispositional mindfulness facets. A sample of 1572 college students completed self-report questionnaires assessing dispositional mindfulness, cannabis use, and internalizing/externalizing symptoms. A cluster analysis based on the facets of dispositional mindfulness (observing, non-judgment, non-reactivity, acting with awareness, and describing) yielded three clusters: a High-Traits cluster (HT), a Non-Judgmentally Aware cluster (NJA), and a Judgmentally Observing cluster (JO). The NJA cluster had a significantly lower frequency of cannabis use and a lower problematic use than the two other clusters. JO and HT clusters, which both have the highest scores of observing, had also the highest levels of cannabis use and problematic use. These results may reflect the enhancement of sensations due to cannabis use. Methodological issues regarding the evaluation of observing facet are discussed.
\end{abstract}

Keywords: cannabis use, substance use, dispositional mindfulness, mindfulness facets 
Dispositional Mindfulness Profiles and Cannabis Use in Young Adults

\section{Introduction}

Cannabis consumption in young adults is a public health issue. Data showed that cannabis is the most frequently used illicit substance among college students in prohibitionist European and USA states (e.g., Arria et al. 2017; Helmer et al. 2014). Cannabis use has been associated with poor outcomes such as academic failure, depression, cognitive impairment, and increased risk of psychoses (Hall 2015; Volkow et al. 2014). Moreover, some findings show a decrease in the perceived risk of using cannabis among youth (e.g., Johnston et al. 2011). Therefore, the prevention, detection, and treatment of cannabis users during the period of adolescence and young adulthood should be a major concern.

Cannabis use disorder (CUD), considered as an externalizing pathology (Krueger et al. 2009), has various determinants that deserve to be studied and treated through transdiagnostic approaches. Among these approaches, Mindfulness-Based Interventions (MBI) have shown their efficacy in the treatment of addictions (Johnson et al. 2016), and more specifically substance use disorders (Chiesa and Serretti 2013) and treatment of relapse or prevention (Bowen et al. 2012). Data suggest that mindfulness practice leads to reduced craving and reactivity to craving (Bowen and Marlatt 2009; Bowen et al. 2009; Brewer et al. 2012; Garland et al. 2012; Zgierska et al. 2009). Furthermore, mindfulness has been negatively associated with both internalizing symptoms (i.e., anxious, depressive, and somatic symptoms) and other externalizing behaviors (i.e., impulsive and disruptive conducts) closely related to substance use disorders (Pepping et al. 2016). MBI could therefore be likely candidates to help individuals dealing with problematic cannabis use.

Mindfulness can be defined as a focused state of awareness on one's present emotions, thoughts, and physical sensations (Kabat-Zinn 1994; Kerr 2016). Dispositional mindfulness (DM) refers to the natural ability to practice mindfulness (for a review, see Rau and Williams 
2014; Tomlison et al. 2017). This ability may vary across individuals and can be improved with practice (Kuyken et al. 2010; Papies et al. 2011). It has been suggested that DM is comprised of five facets: (1) observing, which is the ability to notice internal or external experiences such as sensations, cognitions, emotions; (2) describing, which refers to the capacity to label internal experiments with words; (3) acting with awareness, which refers to focusing attention on one's current activity; (4) non-judgment, which is the adoption of a nonjudgmental attitude towards one's thoughts and feelings; and (5) non-reactivity, which is the tendency to allow thoughts and feelings to be free to come and go without being attached to them (Baer et al. 2006).

Previous studies have shown that DM facets are differently linked to substance use behaviors. The frequency of general substance use has been associated with acting with awareness, non-judgment, and non-reactivity, while observing and describing would be unrelated to substance use behaviors (Karyadi et al. 2014; Levin and Zimmerman 2014). However, the association between DM facets and substance use seems to vary according to the type of substance consumed. For instance, alcohol consumption has been negatively associated with the non-judgment, acting with awareness and describing facets, whereas it does not appear to be associated with the observing facet (Fernandez et al. 2010; Murphy and MacKillop 2012). There are less data for cannabis consumption and results are less consistent. Some studies reported a negative association between cannabis use and DM (e.g., Philip 2010) while another study did not find any significant association with mindfulness facets (Bonn-Miller et al. 2010). Nevertheless, given the promises of MBI in the treatment of externalizing pathologies (Fix and Fix 2013), the exploration of these relationships should be considered cautiously.

In order to better understand outcomes related to DM, current research tends to favor a person-centered approach, including cluster analysis/latent profile analysis, which identifies 
and compares subgroups of individuals sharing similar characteristics within the same sample. This approach assumes that DM includes several dimensions heterogeneously distributed among individuals. This perspective allows for the identification of distinct classes of individuals characterized by different profiles of mindfulness facets. Thus, some studies have highlighted specific profiles of DM in young adults, such as the Judgmentally Observing profile (JO; high on observing, but low on non-judgment and acting with awareness) and the Non-Judgmentally Aware profile (NJA; low on observing, but high on non-judgment and acting with awareness) which have shown to be differently related to life satisfaction and to internalizing symptoms including anxiety, depression, affective instability and distress intolerance (Pearson et al. 2015; Sahdra et al. 2017).

To our knowledge, no study has specifically explored the association of DM with cannabis consumption using a person-centered approach. The empirical data obtained with variable-centered analyses such as factor analysis, structural equation modeling, or multiple regression, have failed to establish a clear relationship between mindfulness facets and cannabis use (Karyadi et al. 2014). Therefore, the main objective of this study was to define homogeneous clusters of participants based on DM facets, using cluster analysis, and to evaluate their link with cannabis use. We expected to (1) replicate DM profiles observed in previous studies, (2) to clarify the link between DM profiles and cannabis use, and (3) to find differences in DM profiles regarding internalizing/externalizing symptoms.

\section{Method}

\section{Participants and procedures}

The data were collected from an online panel recruited on social networks. The link was shared on groups specifically dedicated to college students from different French universities. Participants were 1572 undergraduate including 488 males (31\%) and 1084 females $(69 \%)$, ranged in age from 18 to 28 years old (mean age of males $=20.41$; mean age 
of females $=20.25)$. The study was presented as a survey on human perceptions and behaviors. The participants were assured of the anonymity of their answers and were asked to give their informed consent for participation.

\section{Measures}

DM was assessed using the Five Facet Mindfulness Questionnaire Short Form (FFMQ-SF; Bohlmeijer et al. 2011). The FFMQ-SF is a 24 items 5-point scale ranging from 1 "never or very rarely true" to 5 "very often or always true". It assesses the five following dimensions: observing, defined restrictively in terms of noticing sensations such as sights, sounds, smells, and skin sensations (e.g., "I notice the smells and aromas of things"), describing (e.g., "My natural tendency is to put my experiences into words"), acting with awareness (e.g., "I rush through activities without being really attentive to them", reversecoded), non-reactivity to inner experience (e.g., "I watch my feelings without getting lost in them") and non-judgment of inner experience (e.g., "I tend to evaluate whether my perceptions are right or wrong", reverse-coded). We used the items of the French version of the Five Facet Mindfulness Questionnaire Long Form (Heeren et al. 2011) that have shown good psychometric and structural properties with Cronbach's $\alpha$ coefficient ranging from 0.75 to 0.87 .

Cannabis use in the past six months was assessed using the Cannabis Use Disorders Identification Test-Revised (CUDIT-R; Adamson et al. 2010) which is a self-reported questionnaire of 8 items that assess cannabis use and CUD symptoms (e.g., "How often during the past 6 months did you need to use cannabis in the morning to get yourself going after a heavy session of using cannabis?"). The first seven items are scored from 0 to 4 and the last one was scored 0 or 2 . The total score was used to evaluate "problematic cannabis use" (range: 0-30). Higher total scores indicate greater levels of CUD symptoms. The cut-off score for problematic cannabis use is 13. A French version of the CUDIT-R has shown 
satisfactory internal consistency with Cronbach's $\alpha$ coefficient of 0.89 (Chabrol et al. 2017).

Depressive symptoms were assessed with the Patient Health Questionnaire-9 (PHQ-9; Kroenke et al. 2001; Carballeira et al. 2007), which is a 9 items 4-point scale (e.g., "Little interest or pleasure in doing things"). The French version of the PHQ-9 has shown satisfactory internal consistency (Cronbach's $\alpha=0.86$ ) and measurement equivalence with English form (Athurs et al. 2012).

Cognitive fusion refers to the tendency for behavior to be excessively regulated and influenced by cognition. In this study, it was measured with the Cognitive Fusion Questionnaire (CFQ; Gillanders et al. 2010), which consists of 13 items on a 7-point scale (e.g., "My thoughts cause me distress or emotional pain"). Previous research supports the factor structure, internal consistency (Cronbach's $\alpha=0.93$ ), as well as concurrent and convergent validity of the CFQ's French version (Dionne et al. 2016).

Antisocial behaviors frequency was measured with the Subtypes of Antisocial Behavior Questionnaire (STAB-Q; Burt and Donnellan 2009). The STAB-Q is a 32 items 5point scale assessing three subtypes of antisocial behaviors: rules violation, social aggression, and physical aggression (e.g., "Felt better after hitting"). The French version of the STAB-Q was translated with a back-translation procedure. Discrepancies were discussed, and adjustments to the translation were made.

Depressive symptoms and cognitive fusion were used as external criteria to index internalizing symptoms while rules violation, social aggression, and physical aggression were used to index externalizing behaviors.

\section{Statistical Analyses}

A cluster analysis was performed to extract subgroups of participants based on their DM scores. We then conducted a hierarchical cluster analysis (Ward's method with Euclidean distance) and used the dendrogram and the agglomeration schedule to identify the optimal 
number of clusters. Finally, K-means clustering was used to assign each individual to the identified clusters. Statistical analyses were performed via Statistica 10.

We independently used the first item of CUDIT-R (i.e., "How often do you use cannabis?") to obtain the "cannabis use frequency" score (range: 0-4, scored from 0 "Never" to 4 "More than 3 times a week"). The frequency of cannabis use in each cluster was assessed across the entire sample, while symptoms of problematic use were compared only among cannabis users (at least once in the last six months).

\section{Results}

\section{Descriptive Statistics and Correlations Among Mindfulness Facets and Cannabis use}

All correlations are reported in Table 1. Correlation analysis showed a positive association between cannabis use and the observing facet but negative associations between cannabis use and acting with awareness and non-judgment dimensions. Conversely, observing was weakly related to internalizing and externalizing symptoms while other facets displayed moderate to high correlations with these symptoms. Thirty-three percent of participants $(n=$ 521) reported having used cannabis at least once during the last 6 months. Among cannabis users, participants reported using, on average, between 1 and 4 times a month $(M=1.48 \pm$ 0.77). Means and standard deviations for all variables measured in this study are reported in Tables 2 and 3.

\section{Cluster Analyses}

A three-cluster solution was identified as optimal. The agglomeration schedule showed a sudden increase in linkage distance when three clusters merged to two clusters (from 145.6 to 256.9). This indicates that the passage from three to two clusters would have an important impact on the heterogeneity of the clusters. Clear differences between the three clusters have been identified through a discriminant analysis (Wilks' $\lambda=0.19, p<0.001$ ) with $97.6 \%$ of cases correctly classified. The first cluster $(n=504,32 \%$ of participants $)$ was called 
"Non-Judgmentally Aware cluster" (NJA) as it is characterized by students with a low score on the observing facet $(M=9.40 \pm 2.89)$ and high scores on the acting with awareness $(M=$ $18.39 \pm 3.44)$ and the non-judgment $(M=17.26 \pm 3.94)$ facets (Figure 1$)$. A second cluster $(n$ $=566,36 \%$ of participants $)$ including participants with low non-judgment traits $(M=10.95 \pm$ 3.74) and higher levels of observing traits $(M=14.58 \pm 3.53)$, was therefore named "Judgmentally Observing cluster" (JO). The third cluster ( $n=502,32 \%$ of participants) named "High Trait cluster" (HT), is composed of individuals displaying high scores on all DM facets.

We then compared these clusters on the level of cannabis use, CUD symptoms, and internalizing/externalizing pathology, using ANOVA and Tukey HSD posthoc test (Table 2 and 3). The NJA cluster had a significantly lower frequency of cannabis use than the other two clusters. HT and JO clusters did not differ significantly in their frequency of cannabis use. Similarly, among cannabis users $(n=521)$, NJA cluster displayed a lower level of CUD symptoms than the HT and JO clusters.

\section{Discussion}

This study aimed at a better understanding of the link between DM facets and cannabis use. Based on the evaluation of DM profiles with cluster analysis, we identified three distinct clusters of participants. These clusters were similar in size but displayed significant differences. One of these clusters (NJA) was clearly distinct from the two other clusters on cannabis use. Regarding the replicability of our findings, we can emphasize that our sample seems comparable to other nonclinical populations found in the literature. For example intercorrelations between DM facets are comparable to those presented in a recent metaanalysis (Karyadi et al. 2014) with significant positive associations between acting with awareness/non-judgment, acting with awareness/describing, non-judgment/describing, nonjudgment/non-reactivity, describing/non-reactivity, acting with awareness/non-reactivity; 
significant negative associations between non-judgment/observing and acting with awareness/observing; and a non-significant association between describing/observing. We also found the expected negative correlations between DM facets and externalizing/internalizing symptoms (except for observing). We can also note that the DM profiles found are comparable to those identified in previous studies with a Judgmentally Observing profile (JO) and a Non-Judgmentally Aware profile (NJA) (e.g., Sahdra et al. 2017). The JO profile, which has been associated with many negative emotional outcomes (Pearson et al. 2015), is the one that has shown the highest levels of cannabis use and problematic cannabis use in this study.

In the present study, correlational analyses found significant negative correlations between acting with awareness, non-judgment, and cannabis use/problematic use, and a positive correlation between observing and cannabis use/problematic use. Cluster analyses revealed a different view. We compared the different clusters to identify which combination of DM facets could influence cannabis use. Comparison between HT and NJA clusters suggests that when observing is high, the facets acting with awareness and non-judgment are no longer negatively associated with cannabis use and problematic use, whereas, when observing is at a low level, these facets seem to be negatively associated. Similarly, the JO and HT clusters, which both have the highest levels of observing, have also the highest levels of cannabis use and problematic use, despite different levels of all other facets. This result suggests the need for further investigation of the negative impact of observing, which could neutralize the protective effects of acting with awareness and non-judgment.

However, methodological issues related to the evaluation of observing should be considered when interpreting our results. This facet has already shown unexpected positive relationships with psychological symptoms such as stress, dissociation, and absentmindedness (Baer et al. 2006; Brown et al. 2015). Observing, as operationalized by the FFMQ, may not 
adequately measure mindful observation, because it is restricted to sensations, without exploring emotion awareness nor thought awareness. In this study, observing was positively associated with cognitive fusion and unrelated to depressive symptoms.

Furthermore, the negative association between observing and cannabis use may reflect the influence of use on observing as well as the influence of observing on use. Cannabis consumption could make sensations more vivid and pleasant, mimicking a dispositional aptitude to observe sensations. In the present study, the result that JO and HT clusters both have the highest levels of observing, and of cannabis use and problematic use, may simply reflect the enhancement of sensations due to cannabis use.

This study has several limitations. First, the use of self-report questionnaires can be discussed, although it has shown its validity in the assessment of DM (e.g., Bohlmeijer et al. 2011) and is becoming more and more common in current research (Karyadi et al. 2014). Second, the cross-sectional nature of the data precludes any interpretation regarding the evolution of these processes over time. Third, although there is substantial evidence that Internet data collection methods can produce high-reliability sampling (Ramsey et al., 2016; Walter et al., 2019), the possibility that participant self-selection may have biased the results cannot be excluded. Fourth, since the relationship between mindfulness and substance use may be different in nonclinical versus clinical samples (Bowen and Enkema 2014), our results may not apply to a clinical sample. Fifth, internalizing symptoms were indexed through depression and cognitive fusion. However internalizing spectrum also includes dimensions such as social anxiety, traumatic intrusions, panic, and insomnia that have not been evaluated in this study (Stasik-O’Brien et al. 2019).

\section{Conclusions}

This study may have implications for the prevention and treatment of cannabis use through MBI among college students. Indeed, our results suggest that the various 
combinations of DM facets could be related to cannabis use. In the same way, clinicians should be vigilant and offer interventions that promote body, external events, and emotions and thought awareness, and lead to nonreactive and nonjudgmental observation. Moreover, future studies should include awareness of emotions and thoughts in the evaluation of the observing facet to corroborate our results. Finally, based on the possibility of individualizing mindfulness-based treatments to develop specific facets of DM (Cash and Whittingham 2010), interventions might be proposed to improve the DM facets most significantly associated with a low frequency of cannabis use and non-problematic use. 


\section{References}

Adamson, S. J., Kay-Lambkin, F. J., Baker, A. L., Lewin, T. J., Thornton, L., \& Kelly, B. J. (2010). An improved brief measure of cannabis misuse: The Cannabis Use Disorders Identification Test-Revised (CUDIT-R). Drug and Alcohol Dependence, $110,137-143$.

Arria, A. M., Caldeira, K. M., Allen, H. K., Bugbee, B. A., Vincent, K. B., \& O’Grady, K. E. (2017). Prevalence and incidence of drug use among college students: an 8-year longitudinal analysis. The American Journal of Drug and Alcohol Abuse, 43, 711718.

Arthurs, E., Steele, R. J., Hudson, M., Baron, M., \& Thombs, B. D. (2012). Are scores on English and French versions of the PHQ-9 comparable? An assessment of differential item functioning. PloS one, 7(12), e52028.

Baer, R. A., Smith, G. T., Hopkins, J., Krietemeyer, J., \& Toney, L. (2006). Using self-report assessment methods to explore facets of mindfulness. Assessment, 13, 27-45.

Bohlmeijer, E., ten Klooster, P. M., Fledderus, M., Veehof, M., \& Baer, R. (2011). Psychometric properties of the five-facet mindfulness questionnaire in depressed adults and development of a short form. Assessment, 18, 308-320.

Bonn-Miller, M. O., Vujanovic, A. A., Twohig, M. P., Medina, J. L., \& Huggins, J. L. (2010). Posttraumatic stress symptom severity and marijuana use coping motives: A test of the mediating role of non-judgmental acceptance within a trauma-exposed community sample. Mindfulness, 1, 98-106.

Bowen, S., Chawla, N., Collins, S. E., Witkiewitz, K., Hsu, S., Grow, J., et al. (2009). Mindfulness-based relapse prevention for substance use disorders: a pilot efficacy trial. Substance Abuse, 30, 295-305. 
Bowen S., Enkema M. C. (2014). Relationship between dispositional mindfulness and substance use: Findings from a clinical sample. Addictive Behaviors, 39, 532-537.

Bowen, S., \& Marlatt, A. (2009). Surfing the urge: brief mindfulness-based intervention for college student smokers. Psychology of Addictive Behaviors, 23, 666-671.

Bowen S., Witkiewitz K., Chawla N. (2012). Mindfulness-based relapse prevention: integrating meditation into the treatment of problematic substance use. Mindfulness and Acceptance for Addictive Behaviors: Applying Contextual CBT to Substance Abuse and Behavioral Addictions (eds Hayes SC, Levin ME), 102-28. Context Press.

Brewer, J. A., Elwafi, H. M., \& Davis, J. H. (2012). Craving to quit: psychological models and neurobiological mechanisms of mindfulness training as treatment for addictions. Psycholology of Addictive Behaviors, 7, 366-379.

Brown, K. W., \& Ryan, R. M. (2003). The benefits of being present: mindfulness and its role in psychological well-being. Journal of Personality and Social Psychology, 84, 822848.

Burt S. A., \& Donnellan, M. B. (2009). Development and validation of the Subtypes of Antisocial Behavior Questionnaire. Aggressive Behavior, 35, 376-98.

Carballeira, Y., Dumont, P., \& Borgacci, S. (2007). Criterion validity of the French version of patient health questionnaire (PHQ) in a hospital department of internal medicine. Psychology and Psychotherapy, 80, 69-77.

Cash, M., \& Whittingham, K. (2010). What facets of mindfulness contribute to psychological well-being and depressive, anxious, and stress-related symptomatology? Mindfulness, $1,177-182$.

Chabrol, H., Beck, C., \& Laconi, S. (2017). Contribution of health motive to cannabis highschool students. Addictive Behaviors, 64, 54-56. 
Chiesa, A., \& Serretti, A. (2013). Are mindfulness-based interventions effective for substance use disorders? A systematic review of the evidence. Substance Use \& Misuse, 48, $492-512$.

Dionne, F., Gagnon, J., Balbinotti, M., Peixoto, E. M., Martel, M. E., Gillanders, D., \& Monestès, J. L. (2016). " Buying into thoughts": Validation of a French translation of the Cognitive Fusion Questionnaire. Canadian Journal of Behavioural Science/Revue canadienne des sciences du comportement, 48, 278.

Fernandez, A. C., Wood, M. D., Stein, L. A. R., \& Rossi, J. S. (2010). Measuring mindfulness and examining its relationship with alcohol use and negative consequences, Psychology of Addictive Behaviors, 24, 608-616.

Fix, R. L., \& Fix, S. T. (2013). The effects of mindfulness-based treatments for aggression: A critical review. Aggression and Violent Behavior, 18, 219-227.

Garland, E. L., Boettiger, C. A., Gaylord, S., Chanon, W. V., \& Howard, M. O. (2012). Mindfulness is inversely associated with alcohol attentional bias among recovering alcohol dependent adults. Cognitive Therapy and Research, 36, 441-450.

Gillanders, D. T., Bolderston, H., Bond, F. W., Dempster, M., Flaxman, P. E., Campbell, L., ... \& Masley, S. (2014). The development and initial validation of the cognitive fusion questionnaire. Behavior therapy, 45, 83-101.

Hall, W. (2015). What has research over the past two decades revealed about the adverse health effects of recreational cannabis use? Addiction, 110, 19-35.

Heeren, A., Douilliez, C., Peschard, V., Debrauwere, L., \& Philippot, P. (2011). Crosscultural validity of the Five Facets Mindfulness Questionnaire: Adaptation and validation in a French speaking sample. Revue Européenne de Psychologie appliquée, $61,147-151$. 
Helmer, S. M., Mikolajczyk, R. T., McAlaney, J., Vriesacker, B., Van Hal, G., Akvardar, Y., \& Bewick, B. M. (2014). Illicit substance use among university students from seven European countries: A comparison of personal and perceived peer use and attitudes towards illicit substance use. Preventive Medicine, 67, 204-209.

Johnson, D., Mullen, D., Smith, I. D., \& Wilson, A. (2016). Mindfulness in addictions. BJPsych Advances, 22, 412-419.

Johnston, L. D., O'Malley, P. M., Bachman, J. G., \& Schulenberg, J. E. (2011). Monitoring the future national survey results on drug use, 1975-2010. Volume I: secondary school students. Retrieved from Ann Arbor: Institute for Social Research

Kerr, N. (2016). Mindfulness self-care strategies for clinicians\# 316. Journal of Palliative Medicine, 19, 1226-1227.

Kabat-Zinn, J. (1994). Wherever you go, there you are: Mindfulness meditation in everyday life. New York: Hyperion.

Karyadi, K. A., van der Veen, J. D., \& Cyders, M. A. (2014). A meta-analysis of the relationship between trait mindfulness and substance use behaviors. Drug and Alcohol Dependence, $143,1-10$.

Kroenke, K., Spitzer, R. L., \& Williams, J. B. (2001). The PHQ-9: Validity of a brief depression severity measure. Journal General Internal Medicine, 16, 606-613.

Krueger, R. F., Hicks, B. M., Patrick, C. J., Carlson, S. R., Iacono, W. G., \& McGue, M. (2009). Etiologic connections among substance dependence, antisocial behavior, and personality: modeling the externalizing spectrum. In G. A. Marlatt \& K. Witkiewitz (Eds.), Addictive behaviors: New readings on etiology, prevention, and treatment (pp. 59-88). Washington, DC, US: American Psychological Association. 
Kuyken, W., Watkins, E., Holden, E., White, K., Taylor, R. S., Byford, S., Dalgleish, T., et al. (2010). How does mindfulness-based cognitive therapy work? Behavior Research and Therapy, 48, 1105-1112.

Levin, M. E., Dalrymple, K., \& Zimmerman, M. (2014). Which facets of mindfulness predict the presence of substance use disorders in an outpatient psychiatric sample? Psychology of Addictive Behaviors, 28, 498-506.

Murphy, C., \& MacKillop, J. (2012). Living in the here and now: interrelationships between impulsivity, mindfulness, and alcohol misuse. Psychopharmacology, 219, 527-536.

Papies, E. K., Barsalou, L. W., \& Custers, R. (2012) Mindful attention prevents mindless impulses. Social Psychological and Personality Science, 3, 291-299.

Pearson, M. R., Lawless, A. K., Brown, D. B., Bravo, A. J. (2015). Mindfulness and emotional outcomes: identifying subgroups of college students using latent profile analysis. Personality and Individual Differences, 76, 33-38.

Pepping, C. A., Duvenage, M., Cronin, T. J., \& Lyons, A. (2016). Adolescent mindfulness and psychopathology: The role of emotion regulation. Personality and Individual Differences, 99, 302-307.

Philip, A. C. (2010). More than meditation: The role of dispositional mindfulness in alcohol and marijuana-related problems (Unpublished master's thesis). Auburn University, Auburn, Alabama.

Ramsey, S. R., Thompson, K. L., McKenzie, M., \& Rosenbaum, A. (2016). Psychological research in the internet age: The quality of web-based data. Computers in Human Behavior, 58, 354-360.

Sahdra, B. K., Ciarrochi, J., Parker, P. D., Basarkod, G., Bradshaw, E. L., Baer, R. (2017). Are people mindful in different ways? Disentangling the quantity and quality of 
mindfulness in latent profiles and exploring their links to mental health and life effectiveness. European Journal of Personality, 31, 347-365.

Stasik-O’Brien, S. M., Brock, R. L., Chmielewski, M., Naragon-Gainey, K., Koffel, E., McDade-Montez, E., ... \& Watson, D. (2019). Clinical utility of the Inventory of Depression and Anxiety Symptoms (IDAS). Assessment, 26(5), 944-960.

Volkow, N. D., Baler, R. D., Compton, W. M., Weiss, S. R. B. (2014). Adverse health effects of marijuana use. The New England Journal of Medicine, 370, 2219-2227.

Walter, S. L., Seibert, S. E., Goering, D., \& O’Boyle, E. H. (2019). A Tale of Two Sample Sources: Do Results from Online Panel Data and Conventional Data Converge? Journal of Business and Psychology, 34(4), 425-452.

Zgierska, A., Rabago, D., Zuelsdorff, M., Coe, C., Miller, M., \& Fleming, M. (2008). Mindfulness meditation for alcohol relapse prevention: a feasibility pilot study. Journal of Addiction Medicine, 2, 165-173. 
Table 1 Correlations between variables in the total sample $(N=1572)$

\begin{tabular}{|c|c|c|c|c|c|c|c|c|c|c|c|}
\hline Variable & 1 & 2 & 3 & 4 & 5 & 6 & 7 & 8 & 9 & 10 & 11 \\
\hline 1. Problematic cannabis use & - & & & & & & & & & & \\
\hline 2. Cannabis use frequency & $.86^{*}$ & - & & & & & & & & & \\
\hline 3. Observing & $.14^{*}$ & $.13^{*}$ & - & & & & & & & & \\
\hline 4. Describing & -.01 & -.01 & .03 & - & & & & & & & \\
\hline 5. Acting with awareness & $-.14 *$ & $-.10^{*}$ & $-.14 *$ & $.38^{*}$ & - & & & & & & \\
\hline 6. Non-judgment & $-.10^{*}$ & $-.07 *$ & $-.14 *$ & $.32^{*}$ & $.41 *$ & - & & & & & \\
\hline 7. Non-reactivity & .01 & .02 & $.11^{*}$ & $.25^{*}$ & $.07 *$ & $.25^{*}$ & - & & & & \\
\hline 8. Depression & $.07 *$ & .01 & .04 & $-.35^{*}$ & $-.41 *$ & $-.47 *$ & $-.32 *$ & - & & & \\
\hline 9. Cognitive fusion & $.08^{*}$ & .04 & $.11^{*}$ & $-.39 *$ & $-.41^{*}$ & $-.66^{*}$ & $-.45^{*}$ & $.57 *$ & - & & \\
\hline 10. Rule violation & $.36^{*}$ & $.35^{*}$ & $.10^{*}$ & $-.07 *$ & $-.20 *$ & $-.13^{*}$ & .06 & $.11^{*}$ & $.09 *$ & - & \\
\hline 11. Social aggression & .03 & .03 & $-.08 *$ & $-.10^{*}$ & $-.21 *$ & $-.21 *$ & $-.08 *$ & $.18^{*}$ & $.20^{*}$ & $.31 *$ & - \\
\hline 12. Physical aggression & $.09 *$ & .07 & $-.07 *$ & $-.14^{*}$ & $-.20 *$ & $-.24 *$ & $-.09 *$ & $.26^{*}$ & .24 & $.33^{*}$ & $.47 *$ \\
\hline
\end{tabular}


Table 2 Typology of individuals based on the five dimensions of the FFMQ-SF. Cluster comparison on cannabis use frequency, CUD symptoms, externalizing and internalizing symptoms using ANOVA and post-hoc test

\begin{tabular}{|c|c|c|c|c|c|c|c|c|}
\hline Variables & Sample & Range & $\alpha$ & & Cluster $M(S D)$ & & $F$ & $\begin{array}{l}\text { Significant } \\
\text { comparisons }\end{array}$ \\
\hline & $\begin{array}{c}N=1572 \\
M(S D)\end{array}$ & & & $\begin{array}{c}\text { NJA } \\
(n=504)\end{array}$ & $\begin{array}{c}\mathrm{JO} \\
(n=566)\end{array}$ & $\begin{array}{c}\text { HT } \\
(n=502)\end{array}$ & & \\
\hline Observing & $13.17(4.12)$ & $5-20$ & 0.77 & $9.40(2.89)$ & $14.58(3.53)$ & $15.37(3.07)$ & $525.66^{*}$ & $\mathrm{HT}>\mathrm{JO}>\mathrm{NJA}$ \\
\hline Describing & $15.44(4.26)$ & $5-25$ & 0.75 & $15.48(3.41)$ & $12.52(3.47)$ & $18.70(3.39)$ & $432.86^{*}$ & $\mathrm{HT}>\mathrm{NJA}>\mathrm{JO}$ \\
\hline Acting with awareness & $16.42(4.44)$ & $5-25$ & 0.77 & $18.39(3.44)$ & $12.90(3.56)$ & $18.40(3.71)$ & $428.06^{*}$ & $\mathrm{HT}, \mathrm{NJA}>\mathrm{JO}$ \\
\hline Non-judgment & $15.11(5.00)$ & $5-25$ & 0.82 & $17.26(3.94)$ & $10.95(3.74)$ & $17.66(4.06)$ & $503.98 *$ & $\mathrm{HT}, \mathrm{NJA}>\mathrm{JO}$ \\
\hline Non-reactivity & $14.07(4.32)$ & $5-25$ & 0.79 & $12.50(3.75)$ & $12.82(3.94)$ & $17.05(3.71)$ & $227.55^{*}$ & $\mathrm{HT}>\mathrm{JO}, \mathrm{NJA}$ \\
\hline Frequency of cannabis use & $0,63(0.81)$ & $0-4$ & - & $0.51(0.69)$ & $0.72(0.88)$ & $0.67(0.83)$ & $8.93^{*}$ & $\mathrm{JO}, \mathrm{HT}>\mathrm{NJA}$ \\
\hline Depression & $11.66(5.54)$ & $0-27$ & 0.81 & $10.68(4.72)$ & $15.01(5.22)$ & $8.88(4.67)$ & $223.78 *$ & $\mathrm{JO}>\mathrm{NJA}>\mathrm{HT}$ \\
\hline Cognitive fusion & $49.09(12.23)$ & $6-86$ & 0.78 & $46.46(10.66)$ & $57.46(10.48)$ & $42.29(9.93)$ & $308.73^{*}$ & $\mathrm{JO}>\mathrm{NJA}>\mathrm{HT}$ \\
\hline Rule violation & $2.62(3.67)$ & $0-40$ & 0.73 & $2.09(3.32)$ & $3.24(4.20)$ & $2.47(3.27)$ & $14.04 *$ & $\mathrm{JO}>\mathrm{HT}, \mathrm{NJA}$ \\
\hline Social aggression & $11.65(6.17)$ & $0-44$ & 0.81 & $11.61(6.03)$ & $12.90(6.58)$ & $10.28(5.51)$ & $24.81 *$ & $\mathrm{JO}>\mathrm{NJA}>\mathrm{HT}$ \\
\hline Physical aggression & $9.84(6.87)$ & $0-40$ & 0.84 & $9.88(6.62)$ & $11.42(7.38)$ & $8.03(6.06)$ & $33.57 *$ & $\mathrm{JO}>\mathrm{NJA}>\mathrm{HT}$ \\
\hline
\end{tabular}

NJA: Non-Judgmentally Aware cluster; JO: Judgmentally Observing cluster; HT: High Traits cluster.

$* p<.01$ 
Table 3 Mean, standard deviations for CUD symptoms among cannabis users $(n=521)$. Cluster comparison using ANOVA and post-hoc test.

\begin{tabular}{|c|c|c|c|c|c|c|c|c|}
\hline \multirow[t]{2}{*}{ Variable } & Total subsample & Range & $\alpha$ & NJA & $\mathrm{JO}$ & HT & $F$ & Significant comparisons \\
\hline & $n=521$ & & & $n=138$ & $n=206$ & $n=177$ & & \\
\hline CUD symptoms & $5.83(5.72)$ & $1-29$ & 0.88 & $4.39(4.45)$ & $6.86(6.82)$ & $5.77(4.93)$ & $7.93^{*}$ & $\mathrm{JO}, \mathrm{HT}>\mathrm{NJA}$ \\
\hline
\end{tabular}

NJA: Non-Judgmentally Aware cluster; JO: Judgmentally Observing cluster; HT: High Traits cluster.

$* p<.01$ 
1

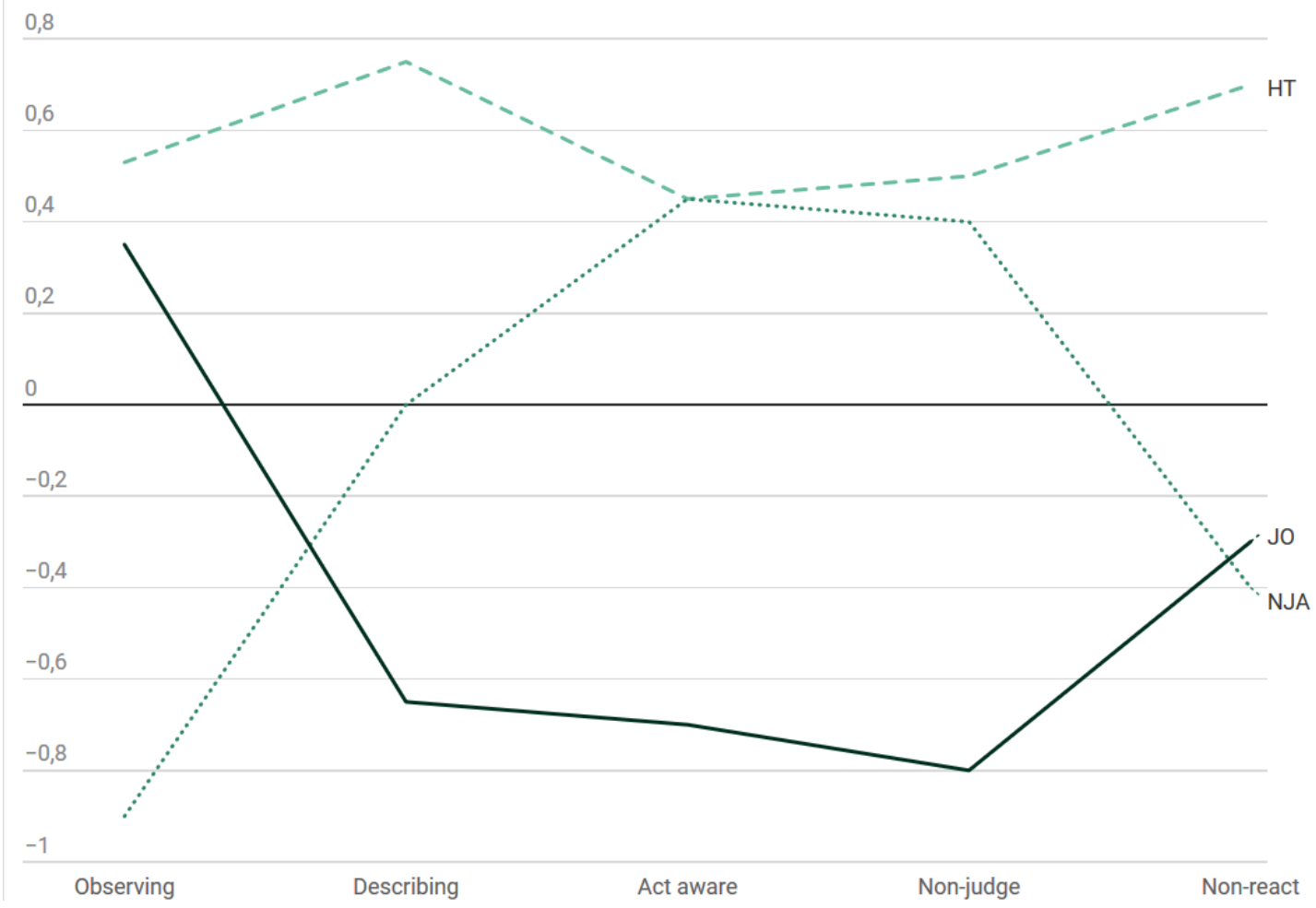

Fig. 1 Three-cluster solution based on $z$-scores for the FFMQ-SF dimensions indicated on the $x$-axis. NJA: Non-Judgmentally Aware cluster. JO: Judgmentally Observing cluster. HT: High Traits cluster 